\title{
Residual stresses of the as-cast Mg-xCa alloys with hot sprues by neutron diffraction
}

\author{
Jiangfeng Song ${ }^{a}$, Yuanding Huang ${ }^{b}$, Karl Ulrich Kainer ${ }^{c}$, Weimin Gan ${ }^{d, ~}$ * \\ and Norbert Hort ${ }^{\mathrm{e}}$ \\ Institute of Materials Science, Helmholtz-Zentrum Geesthacht, Max-Planck-Strasse 1, D-21502 \\ Geesthacht, Germany
}

ajiangfeng.song@hzg.de, byuanding.huang@hzg.de, 'karl.kainer@hzg.de, 'weimin.gan@hzg.de, enorbert.hort@hzg.de

Keywords: Mg-Ca alloy, solidification, hot tearing, residual stress, hot sprue

\begin{abstract}
Residual stresses in $\mathrm{Mg}-\mathrm{xCa}(0.5 \mathrm{wt} . \%$ and $1.0 \mathrm{wt} . \%)$ cast alloys were investigated by neutron diffraction using a mould with two preheating temperatures of $250{ }^{\circ} \mathrm{C}$ and $450{ }^{\circ} \mathrm{C}$. Results show that the increase of $\mathrm{Ca}$ content decreases the residual stress in the hot sprue region. These results are quite in agreement with those obtained by the measurement of hot tearing susceptibility, which shows the increment in $\mathrm{Ca}$ content improves the castability of $\mathrm{Mg}-\mathrm{Ca}$ alloys.
\end{abstract}

\section{Introduction}

Hot tearing or hot cracking is often a major casting defect and have significant impact on the quality of casting products. For the subsequent processing or service, those components free from casting defects and with a very low residual stress are preferred. All thermal contraction associated with decreasing temperature and the change in materials state exerts thermal stress during casting. Thermal stress involves different consequences such as distortion, crack, hot tear, and residual stress [1]. Hot tearing is a complex solidification phenomenon which is still not fully understood, though various mechanisms have been proposed [2].

Research on magnesium alloys is getting more attractive in recent years due to their potential in 3C (consumer, computer, communication) and automotive industries [1]. Most previous studies on hot tearing susceptibility were carried out on alloys series like Mg-Al [2, 3], Mg-Zn [4] and Mg-RE (Rare Earths) [5-7]. Different to aluminum alloys and steels, magnesium alloys have low elastic constants. Therefore, a very small residual stress can cause the distortion of casting components. Previous investigations on hot tearing of $\mathrm{Mg}-\mathrm{Al}$ and $\mathrm{Mg}-\mathrm{Zn}$ alloys have shown that casting defects such as hot cracks could occur at the hot spot due to accumulation of thermal stresses during solidification.

The alloying element $\mathrm{Ca}$ plays a quite important role in adjusting the mechanical properties of structural or medical magnesium alloys [3, 8-10]. The addition of $\mathrm{Ca}$ in $\mathrm{AZ}$ alloys improves the creep resistance due to the formation of thermal stable intermetallic $\mathrm{Al}_{2} \mathrm{Ca}$ [10]. Owing to that both $\mathrm{Mg}$ and $\mathrm{Ca}$ have an excellent biocompatibility, $\mathrm{Mg}$-Ca alloys are being considered as the potential degradable biomaterials [11]. The present investigation quantifies the distribution of residual stress in castings of $\mathrm{Mg}-\mathrm{Ca}$ alloys using neutron diffraction from the point of view of their castability. Neutron diffraction for stress analysis is preferred because of its high penetration depth and flexible gauge volume choices for coarse grained as-cast ingot. Furthermore, it is also possible to perform an in-situ strain study during the solidification process with high flux reactor source. The obtained thermal stress distribution is used to evaluate the formation of hot tearing in $\mathrm{Mg}-\mathrm{Ca}$ alloys in combination with the experimental results.

\section{Experimental}

The ingots for the neutron diffraction measurement were prepared using the setup of hot tearing evaluation system which was discussed in detail elsewhere [12]. A cylindrical mild steel crucible coated with hexagonal $\mathrm{BN}$ was used for melting in an electrical resistance furnace. High purity Ar + $0.2 \% \mathrm{SF}_{6}$ protective gas mixture was used for melt protection. Pure magnesium $(99.9 \mathrm{wt} . \%$.) and 
calcium (99.6 wt. \%) were used as starting materials. Calcium was added to the melt at $700{ }^{\circ} \mathrm{C}$. The melt was stirred for $5 \mathrm{~min}$. manually. Then the melt was held at the pouring temperature for about 5 min before casting. The pouring temperature was set at $100{ }^{\circ} \mathrm{C}$ above the liquids temperature. The melt was poured into a mould coated with a thin layer of $\mathrm{BN}$, which was preheated to the temperature of $250{ }^{\circ} \mathrm{C}$ and $450{ }^{\circ} \mathrm{C}$. The macroscopic picture of a typical casting ingot is shown in Fig. 1 (a). The end of the casting was fixed to a certain position to simulate the constraint shrinkage, as marked with arrow. For comparison, a sample was cast without constraint shrinkage. The upper head (marked with red dashed box and white arrow in Fig.1 (a)) was later machined off, and the rest (both the sprue and rod, also marked in Fig. 1 (a)) was used for the diffraction. All the samples used for stress measurements were in the same size. In this study, two Ca contents $(0.5 \mathrm{wt}$. $\%$ and $1.0 \mathrm{wt}$. \% $)$ were selected. The stress-free reference sample was machined from the head as a disk of $\varnothing 2 \times 2 \mathrm{~mm}^{2}$ from each $\mathrm{Mg}$-Ca alloy. The microstructures of transversal cross-section of the rod near the junction area were checked by Optical microscopy (OM). The samples were cold mounted, ground with $\mathrm{SiC}$ sandpaper until 2500, polished with water free OPS and $1 \mu \mathrm{m}$ diamond suspension, etched with picric acid. OM was performed with a LEICA DMI5000 M microscope. The grain size was measured by linear intercept method.

Neutron diffractometer STRESS-SPEC at FRM II (Heinz Maier-Leibnitz Zentrum, Garching, Germany) was used to measure the residual strain [13]. The measurements were performed at room temperature. A wavelength of $0.147 \mathrm{~nm}$ produced by Ge (311) monochromator was selected to measure the peak position variation of (21.1) planes of $\mathrm{Mg}$. The investigated gauge volume $3 \times 3 \times 2$ $\mathrm{mm}^{3}$ was controlled using a primary slit of $3 \times 3 \mathrm{~mm}^{2}$ and a radial collimator with FWHM (full width of half maximum $)=2 \mathrm{~mm}$. Fig. 1 (b) shows the setup for strain scanning. Three dimensional stress measurements are also illustrated. Due to relatively large grains of the cast ingot, the sample was oscillated around $\Omega$ angle with amplitude of $\pm 5^{\circ}$. An $8 \mathrm{~mm}^{3}$ cubic sample cut from the ingot was used as the stress-free reference.

Triaxial strain scanning (radial, hoop, and axial) was carried out with a step size of $10 \mathrm{~mm}$ through the central line of sprue and rod. The lattice strain $\left(\varepsilon_{h k l}\right)$ for the (21.1) reflection at a constant wavelength was calculated by,

$$
\varepsilon_{h k l}=\frac{d_{h k l}-d_{h k l}^{0}}{d_{h k l}^{0}}=\frac{\sin \theta_{h k l}^{0}}{\sin \theta_{h k l}}-1
$$

where $d_{h k l}$ is the lattice spacing of (21.1) planes in the residual stressed materials and $\theta_{h k l}$ the corresponding diffraction angle, $d_{h k l}^{0}$ is the lattice spacing of $h k l$ planes in the stress-free materials and $\theta_{h k l}^{0}$ the corresponding diffraction angle. With Hook's law the residual stress was then calculated using Young's modulus of $44 \mathrm{GPa}$ and Poisson's ratio of 0.293.
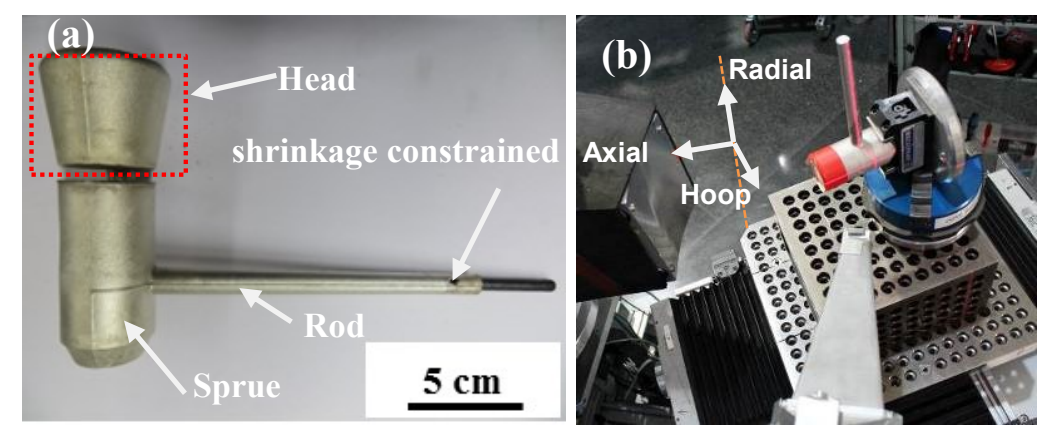

Fig. 1 (a) Macroscopic picture of a typical casing; (b), View of the instrument setup at STRESS-SPEC for the axial direction strain scanning of the Mg- $1.0 \mathrm{wt} . \%$ Ca sample.

\section{Results and discussions}

The microstructures (perpendicular to the hoop direction) of $\mathrm{Mg}-0.5 \mathrm{wt} . \% \mathrm{Ca}$ and $\mathrm{Mg}-1.0 \mathrm{wt} . \%$ $\mathrm{Ca}$ alloys cast at $450{ }^{\circ} \mathrm{C}$ are shown in Fig. 2 (a) and (b), with an average grain size of $370 \pm 115 \mu \mathrm{m}$ and $185 \pm 59 \mu \mathrm{m}$, respectively. 
Distribution of the triaxial residual stresses (radial, hoop, and axial) along the central line for $\mathrm{Mg}-1.0$ wt. \% Ca alloy with a mold temperature of $250^{\circ} \mathrm{C}$ is plotted in Fig. 3(a). The sample was cast without constraint shrinkage. The position of junction area is marked by the red dashed line. Both the radial and hoop stresses show similar variations from left to right of rod end. There is barely any stress from the junction to the end of the rod. The casting ingot for the residual stress measurement is shown in Fig. 3(b), as can be seen, the sample is freely contracted during solidification. No evidence of crack was found at the junction area. For normal constrained shrinkage casting, it is totally broken at the junction area due to the high stress concentration (Fig. 3(c)).
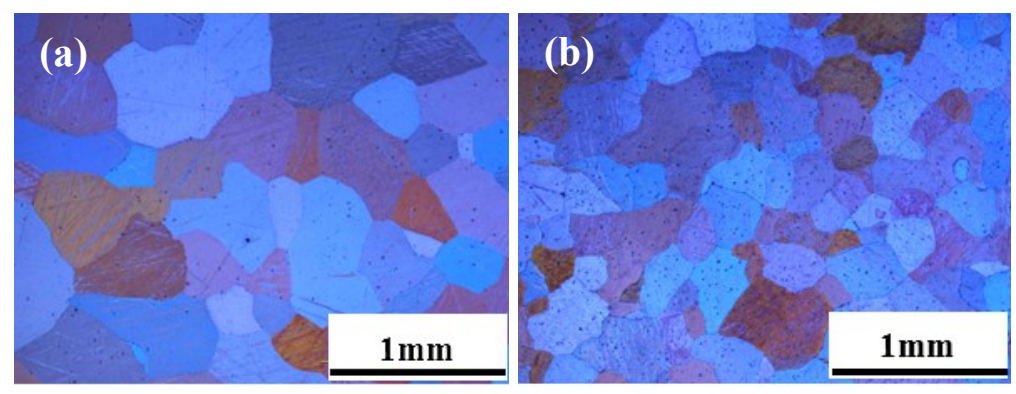

Fig. 2 Optical microstructures of alloys at the mould temperature of $450{ }^{\circ} \mathrm{C}$, (a) $\mathrm{Mg}-0.5$ wt. \% Ca, (b) Mg-1.0 wt. \% Ca.
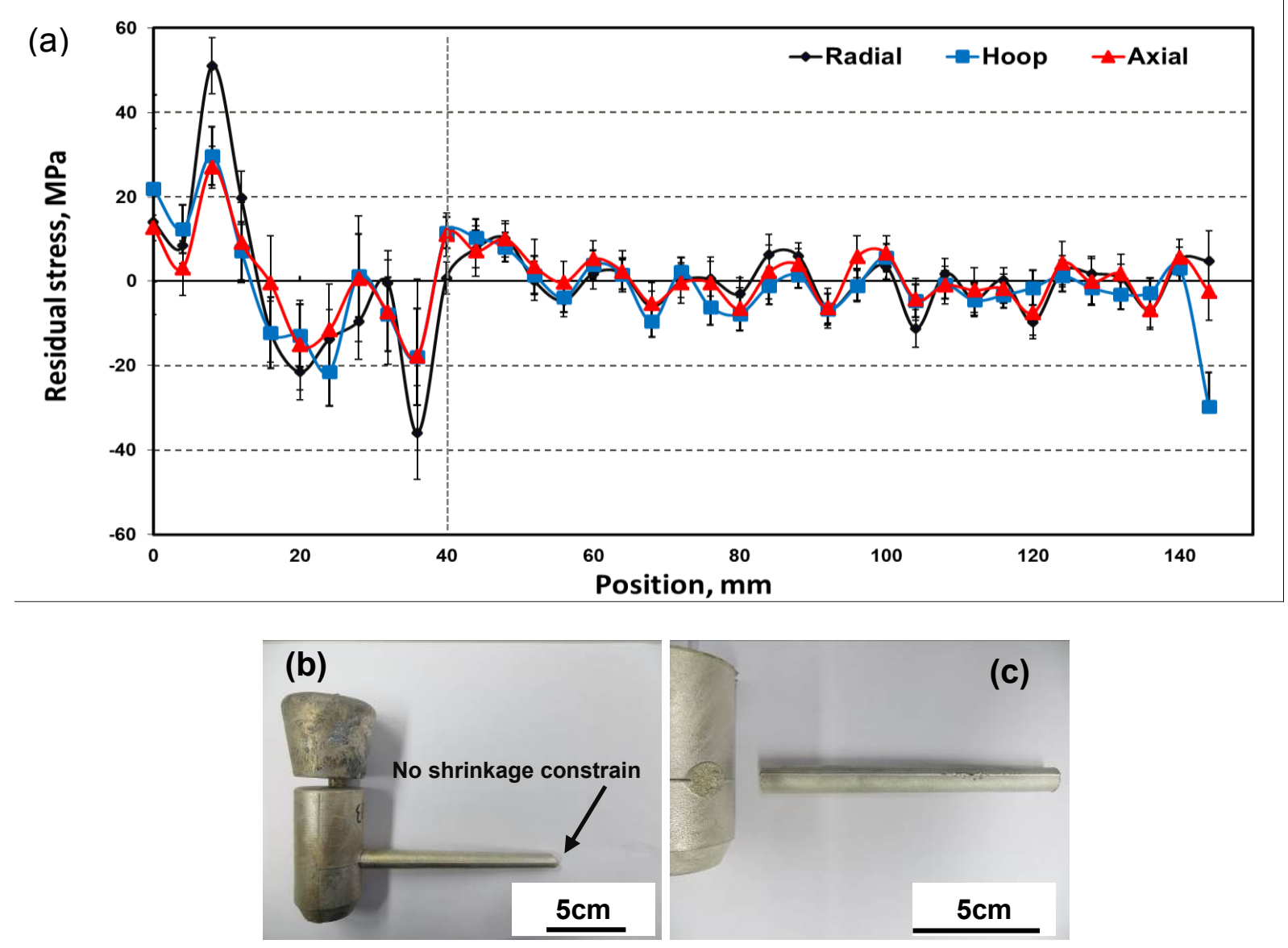

Fig. 3 (a) Triaxial residual stress distribution of the Mg-1.0 wt. \% Ca casting at the mould temperature of $250^{\circ} \mathrm{C}$; macroscopic pictures of casings (b) free shrinkage (for stress measurement),

(c) constrained shrinkage.

During the last stage of solidification, the thermal contraction of dendrites is hindered by the previously solidified dendrites, which results in a tensile stress. This tensile stress caused by non-uniform thermal contraction of the coherent dendrites might generate gaps and cavities. If the 
liquid can flow freely, the gaps and cavities will be filled up with the residual liquid. These microscopic defects will be "healed", and thus hot cracks will not appear [14]. In case the liquid cannot flow freely in the constrained shrinkage casting, the stresses will pile up at the weak area (e.g., the junction area for this kind of mould) and finally result in hot crack. The freely contracted Mg-1.0 wt. $\% \mathrm{Ca}$ cast at a mould temperature of $250^{\circ} \mathrm{C}$ shows no obvious stress concentration, which is in good agreement with its hot tearing susceptibility.

Fig. 4 shows the distribution of triaxial residual stress along the central line of $\mathrm{Mg}-1.0 \mathrm{wt} . \% \mathrm{Ca}$ at a mould temperature of $450{ }^{\circ} \mathrm{C}$. The sample was cast under constrained shrinkage. All the radial, hoop and axial stresses exhibit similar trend from the junction area to the end of the rod. From left surface to the junction the residual stress exhibits first as tensile then as compressive and then again as tensile type. The maximum compression stresses appear around at position $20 \mathrm{~mm}$, which are $50 \pm 9 \mathrm{MPa}, 28$ $\pm 7 \mathrm{MPa}$ and $48 \pm 7 \mathrm{MPa}$ for redial, hoop and axial, respectively. Then the stresses increase and change to tensile stresses, reach the maximum at position $36 \mathrm{~mm}$ (4 $\mathrm{mm}$ away from the junction area), which are $53 \pm 5 \mathrm{MPa}, 20 \pm 6 \mathrm{MPa}$ and $35 \pm 7 \mathrm{MPa}$ for redial, hoop and axial, respectively. Among the three kinds of residual stresses, the radial stress showed the highest value.

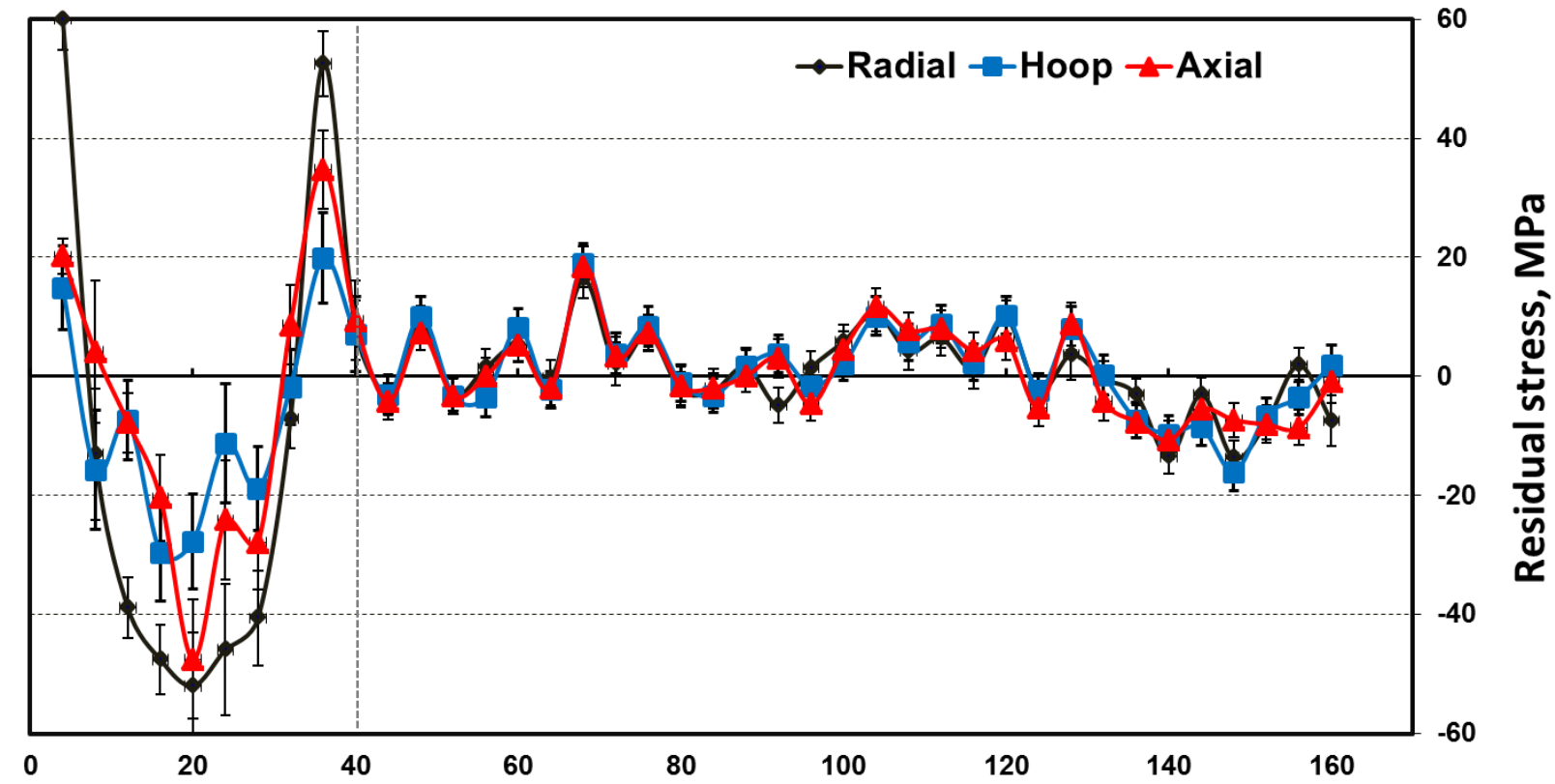

Fig. 4 Triaxial residual stress distribution of the $\mathrm{Mg}-1.0$ wt. \% Ca sample at the temperature of $450{ }^{\circ} \mathrm{C}$.

As illustrated above, the tensile residual stress may finally result in hot crack. The tensile residual stress detected in $\mathrm{Mg}-1.0$ wt. \% Ca at $450{ }^{\circ} \mathrm{C}$ indicates that, there is a high risk to produce the hot cracks at the junction area. Comparing the $\mathrm{Mg}-1.0$ wt. \% $\mathrm{Ca}$ samples cast at different mould temperatures, the sample cast at $250^{\circ} \mathrm{C}$ is completely broken at the junction. While the casting at 450 ${ }^{\circ} \mathrm{C}$ shows no visible crack at the junction area, it still exists high tensile stress. Consequently, the sample with a lower mould temperature of $250^{\circ} \mathrm{C}$ shows a higher hot tearing tendency. The sample cast with a lower mould temperature has a higher thermal gradient which can cause a higher internal thermal stresses. As a result, the initiation and propagation of hot crack are promoted [15].

The triaxial residual stress distribution of $\mathrm{Mg}-0.5 \mathrm{wt} . \% \mathrm{Ca}$ at mould temperature of $450{ }^{\circ} \mathrm{C}$ is shown in Fig. 5. This sample was also cast under constrained shrinkage. For comparison, all the radial, hoop and axial stresses are analyzed along the central line. Due to relatively coarse grains in the ingot the calculated stress has a large error bar. However, no obvious residual stress is evidenced along the detected line for all the three directions. This might be due to the fact that a small crack can be found at the junction area, as show in Fig. 6(a) and (b), pointed by the arrow. As the hot crack initiates and propagates, the piled up stress releases simultaneously. As a result, the residual stress is 
not obvious, which is in agreement with the experimental results. Nevertheless, $\mathrm{Mg}-0.5 \mathrm{wt} . \% \mathrm{Ca}$ still exhibits a higher hot tearing susceptibility than $\mathrm{Mg}-1.0$ wt. \% Ca. A higher content of $\mathrm{Ca}$ in $\mathrm{Mg}-\mathrm{Ca}$ alloys provides more eutectic phases at the final stage of solidification, which is beneficial for "healing" of the hot crack, in other words, for suppressing the hot tearing susceptibility. However, this need more detailed investigations, which are still in work.

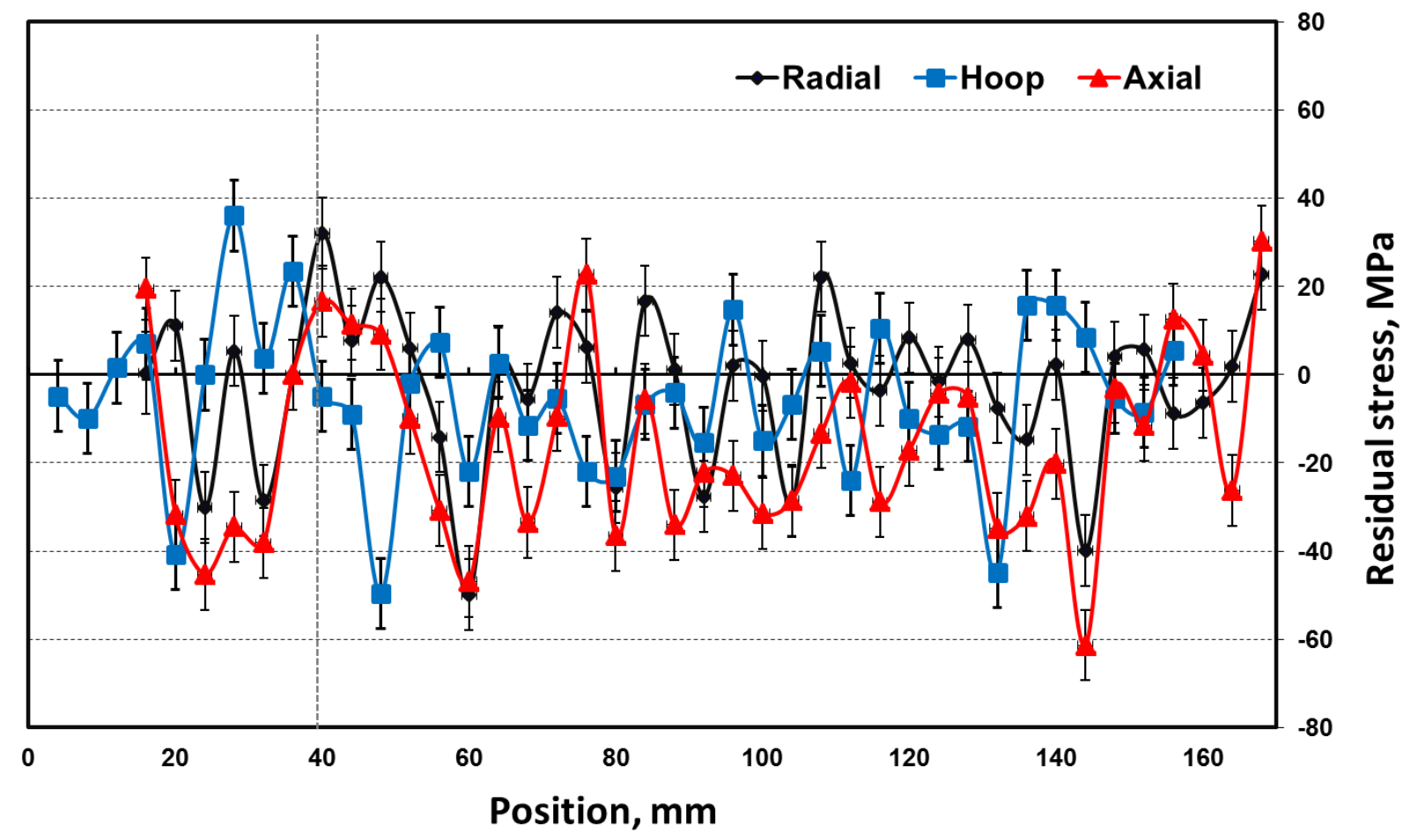

Fig. 5 Triaxial residual stress distribution of the Mg- 0.5 wt. \% Ca sample at the mould temperature of $450{ }^{\circ} \mathrm{C}$.

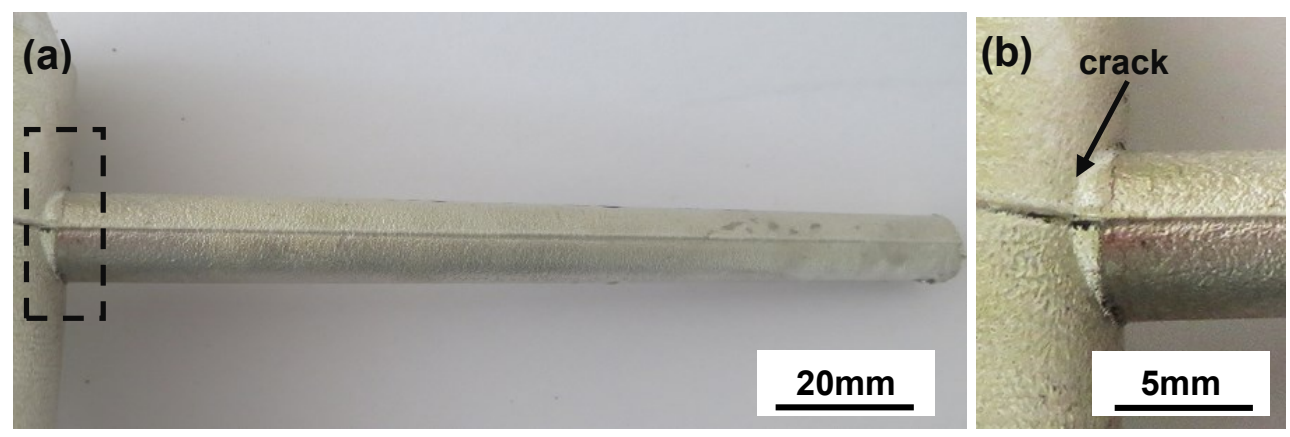

Fig. 6 (a) Macroscopic picture of Mg- 0.5 wt. \% Ca sample at a mould temperature of $450{ }^{\circ} \mathrm{C}$, (b) close up of the junction area.

\section{Summary}

Neutron diffraction was successfully introduced to measure the residual stress in $\mathrm{Mg}$-Ca hot tearing ingots with relatively coarse grains. The obtained results are in good agreement with the hot tearing tendency results. Hot crack will not appear in freely contracted castings during solidification. High mould temperature will decrease the hot tearing tendency as well as the higher content of $\mathrm{Ca}$ for Mg-Ca alloys. 


\section{References}

[1] K.U. Kainer, Magnesium Alloys and Technology, Wiley-VCH GmbH, Weinheim, Germany 2003.

[2] Z.S. Zhen, N. Hort, Y.D. Huang, O. Utke, N. Petri, K.U. Kainer, Hot tearing behaviour of binary Mg-1Al alloy using a contraction force measuring method, Inter.J. of Cast Metals Res. 22 (2009) 331-334.

[3] Y.S. Wang, B.D. Sun, Q.D. Wang, Y.P. Zhu, W.J. Ding, An understanding of the hot tearing mechanism in AZ91 magnesium alloy, Mater. Lett. 53 (2002) 35-39.

[4] L. Zhou, Y.D. Huang, P.L. Mao, K.U. Kainer, Z. Liu, N. Hort, Influence of composition on hot tearing in binary $\mathrm{Mg}-\mathrm{Zn}$ alloys, Inter. J. of Cast Metals Res. 24 (2011) 170-176.

[5] Z. Wang, Y. Huang, A. Srinivasan, Z. Liu, F. Beckmann, K. Kainer, N. Hort, Experimental and numerical analysis of hot tearing susceptibility for Mg-Y alloys, J. of Mater. Sci. 49 (2014) 353-362.

[6] Z. Wang, Y. Huang, A. Srinivasan, Z. Liu, F. Beckmann, K.U. Kainer, N. Hort, Hot tearing susceptibility of binary Mg-Y alloy castings, Mater. \& Des. 47 (2013) 90-100.

[7] Z. Wang, Y.D. Huang, A. Srinivasan, Z. Liu, K.U. Kainer and N. Hort, Influences of Y Additions on the Hot Tearing Susceptibility of Mg-1.5wt.\%Zn Alloys, Mater. Sci. Forum. 765 (2013) 306-310.

[8] Q.D. Wang, W.D. Chen, X.Q. Zeng, Y.Z. Lu, W.J. Ding, Y.P. Zhu, X.P. Xu and M. Mabuchi, Effects of $\mathrm{Ca}$ addition on the microstructure and mechanical properties of AZ91magnesium alloy, J. of Mater. Sci. 36 (2001) 3035-3040.

[9] W.-C. Kim, J.-G. Kim, J.-Y. Lee and H.-K. Seok, Influence of Ca on the corrosion properties of magnesium for biomaterials , Mater. Lett. 62 (2008) 4146-4148.

[10] A.A. Luo, M.P. Balogh and B.R. Powell, Creep and microstructure of magnesium-aluminum-calcium based alloys, Metall Mater Trans A. 33 (2002) 567-574.

[11] Y. Wan, G. Xiong, H. Luo, F. He, Y. Huang and X. Zhou, Preparation and characterization of a new biomedical magnesium-calcium alloy, Mater. \& Des. 29 (2008) 2034-2037.

[12] Z.S. Zhen, N. Hort, Y.D. Huang, N. Petri, O. Utke and K.U. Kainer, Quantitative Determination on Hot Tearing in Mg-Al Binary Alloys, Light Metals Technology 2009. 618-619 (2009) 533-540.

[13] M. Hofmann, J. Rebelo-Kornmeier, U. Garbe, R. C. Wimpory, J. Repper, G. A. Seidl, H. G.Brokmeier and R. Schneider, Stress Spec: Advanced Materials Science at the FRM II, Neutron News, 18 (2007)27-30.

[14] L. Katgerman and D.G. Eskin, In search of the prediction of hot cracking in aluminium alloys, Springer Berlin Heidelberg, Germany. (2008) 11-26.

[15] S. Lin, A study of hot tearing in wrought aluminium alloys, $\mathrm{PhD}$ thesis, University of Québec at Chicoutimi, Canada. 1999. 